\title{
AS RELAÇÕES FAMILIARES NA POESIA DE CARLOS DRUMMOND: AFETO E SOLIDARIEDADE
}

RESUMO :

A releitura da obra de Carlos Drummond de Andrade proposta nessa pesquisa busca resgatar a história afetivo-familiar dos Drummond de Andrade, a partir dos textos poéticos. Pretende revelar o ente comum presente na pessoa mítica do poeta $e$ suas ligações familiares, sob as vertentes de afeto $e$ sol idariedade pesquisadas na obra e em documentos como cartas, diários, depoimentos.

Palavras-chave: poesia, Drummond, família, afeto, solidariedade.

A linha de pesquisa em que a Dissertação se insere é Literatura, História e Memória Cultural, o que nos permitiu articular ficção, experiência vivida e organização social em torno da obra de Carlos Drummond de Andrade, tratando as memórias poéticas também como memórias de um grupo, mas ressalvando nessa peculiaridade, a universalidade da obra.

A idéia de realizar a pesquisa nasceu de uma conjunção oportuna de fatores: da proximidade com parentes de Carlos Drummond de Andrade, do fato de viver em Itabira ${ }^{1}$ lecionando Literatura há mais de vinte anos e, por fim, de um contato direto com público diversificado, ao trabalhar na Seção de Memória Viva do Memorial Carlos Drummond de Andrade. Este último fator possibilitou-me ministrar cursos, oficinas, palestras, para itabiranos e também para visitantes de diferentes regiões que buscam a terra natal do poeta.

Trabalhando com públicos de faixas etárias e condições sócio-econômicas e culturais diferentes foi possivel perceber seu interesse por dados biográficos

* Mestre em Letras: Estudos Literários (Área de concentração: Literatura Brasileira), 2003. 


\section{EMTESE}

Belo Horizonte, v. 8, p. I-243, dez. 2004

relevantes do escritor. (No espaço do Memorial citado, havia uma exposição de dezenove painéis ${ }^{2}$ sobre personagens do poema "A mesa", o que provocava a curiosidade das pessoas em relação à famîlia real do poeta.) Diante do poema em intertextualidade com as telas, as pessoas perguntavam sobre o número de filhos do casal, se algum deles foi fazendeiro; se havia, na realidade, uma irmã chamada Rosa Amélia, como no poema; se havia, um irmão "bacharel". Tais perguntas incentivaram-me à procura desses dados em outros textos de Drummond, em jornais da época e em documentos de cartório.

As primeiras respostas encontradas foram decisivas para a formulação da pergunta básica para a pesquisa: "É possível resgatar os laços afetivos familiares dos Drummond de Andrade, tendo por roteiro os textos poéticos?"

Delineada a hipótese e definidos os principais textos, o passo seguinte foi a aproximação com familiares de Drummond que detêm conhecimentos muito específicos sobre o contexto da época, costumes da família e da região. Isso ocorreu, gradativamente, através de contatos pessoais e de intensa pesquisa em cartas, cartões, dedicatórias, documentos pessoais, resultando em descoberta de cartas inéditas, de manuscritos, fotografias e informações que ajudam a "iluminar" vários textos.

Um achado significativo também no sentido de me orientar foi uma frase do escritor gaúcho, Walmir Ayala ${ }^{3}$, que sintetiza bem a essência, o jeito de ser, tanto do poeta, quanto dos familiares que conheci: "Esse teu jeito mineral e seco esconde muito mel, meu querido Drummond." Esse "mel escondido", ou seja - o afeto -constitui o cerne da pesquisa; um afeto que não faz alarde, mas se encontra substancialmente enraizado e presente na obra.

Ao constatar que dados relevantes da história familiar de Carlos Drummond vislumbrados em textos literários levavam a maior aproximação entre leitor e obra, encaminhei a pesquisa do Mestrado nessa direção: a da possibilidade de se resgatar os vínculos familiares através de poemas, contos e crônicas menos conhecidos do público leitor - textos literários que dialogassem com os documentos mencionados.

Outra percepção importante propiciada pelo contato com leitores de Drummond foi sobre a visão construída no imaginário das pessoas com relação à obra e ao escritor. Para um grande número delas, Carlos Drummond é "um poeta inteligente", mas "difícil de ser lido", um tanto "hermético, melancólico, pessimista". 
Esses foram adjetivos citados por muitos participantes de palestras e oficinas em várias cidades mineiras.

Diante desses adjetivos, uma reflexão se faz necessária. Focalizando a queixa sobre a "dificuldade" de ser lido - mencionada por estudantes "vestibulandos" - talvez essa ocorra, devido à utilização de poemas complexos, em provas de vestibular, nas quais o principal objetivo é el iminar o máximo de candidatos e não, analisar efetivamente os textos, considerando a Literatura como a arte que é. Convém lembrar que o poeta não escreveu (e talvez nunca aceitasse escrever poemas) para aquela finalidade.

Quanto ao termo "pessimista", ao lermos diversos críticos e observarmos livros didáticos de ensino médio, percebemos que tem predominado, por parte de autores, na seleção e análise dos textos de Drummond, um enfoque mais direcionado a temas que remetem à solidão, ao pessimismo, à melancolia (textos contemporâneos à guerra mundial.) Não negamos a existência dessa face também importante em sua poética, entretanto consideramos que o aluno pode ser influenciado por esse recorte.

Sobre a "complexidade", concordamos que há textos complexos, e é importante que existam; queremos ressaltar, entretanto, que há também inúmeras opções de textos mais simples e adequados tanto ao interesse de crianças, como ao de jovens ou adultos. Tais textos, aparentemente simples - não simplificados - permitem abordagens diferenciadas, seja com público leitor que tenha pouca experiência de leitura, seja com o leitor proficiente, dependendo do nível de aprofundamento pretendido pelo professor. Como afirma Guilherme de Figueiredo4, a poesia de Drummond ensina a ler:

"[...] Raros escritores souberam como ele colher um vocábulo e transformá10 numa rosa ou num relâmpago[...] A poesia de Drummond ensina o leitor a ler." [...] Porque falou simplesmente de nosso cotidiano, do seu cotidiano, do seu eu de todos os dias, o seu pão-nosso, a nossa miséria-sua, a suanossa fragilidade diante da brutalidade da vida, e da vida brasileira, a gota de mel da esperança e o travo amargo da fome, a casa, a árvore, o amigo, a andorinha, a amendoeira[...]"

A experiência vivida como aluna e, posteriormente, professora na área de Letras, trouxe-me a percepção de que havia (e talvez ainda haja) uma espécie de receio, por parte dos professores, de trabalhar poesia, sem terem um "respaldo" do 


\section{EMTESE}

Belo Horizonte, v. 8, p. I-243, dez. 2004

livro didático, isto é, sem terem à mão uma análise prévia do poema, feita por alguma "autoridade"no assunto. Era comum ouvir de colegas: "Drummond é difícil demais para esses meninos".

E assim, devido talvez ao receio de não ter respostas para todas as perguntas dos alunos, ou ao desconhecimento de outros textos, durante muitos anos, os poucos poemas de Drummond levados às aulas eram sempre os mesmos: "Quadrilha", "No meio do caminho", "José" e "Confidência do Itabirano", acompanhados de questionários dos livros didáticos, muitas vezes, sem a devida contextualização e adequação das perguntas para aquela turma ou faixa etária; sem o tempo e a liberdade necessários para que o aluno "sentisse" o texto.

Esse tipo de abordagem - agravado pela redução de uma obra tão extensa a quatro ou cinco poemas - além de restringir a possibilidade de uma leitura mais livre e a participação do leitor, pode contribuir para a criação de imagens equivocadas sobre o escritor e sua produção.

Também, por parte de significativo número de itabiranos, observamos certa indiferença, em relação à pessoa Carlos Drummond, justificada, verbalmente, por uma espécie de estigma de "filho ilustre, mas ingrato, que abandonou sua terra" - incompreensão que alimenta muitas lendas. Analisando as causas dessa apatia e até mesmo "aversão" ao nome e à obra do poeta por conterrâneos, constatamos sua origem: o desconhecimento da existência de inúmeros textos dedicados a Itabira e Minas.

Percebida a necessidade de trabalhar textos drummondianos, na cidade natal do poeta, (não em forma de palestras, mas de maneira diferenciada, participativa) ampliamos as possibilidades de conhecimento do leitor através de textos variados, em forma de Oficinas que incluiam também recursos de outras artes ${ }^{5}$. E a quase certeza de que seria possivel mudar a imagem existente, através dos próprios textos de Carlos Drummond, tornou-se realidade, verificada nos questionários de avaliação dos participantes, dentre eles, quatrocentos professores, muitos dos quais passaram a levar aos alunos textos humorísticos, ecológicos, afetivos, irônicos, ecumênicos. Encenações de crônicas e saraus passaram a acontecer, na cidade, numa comprovação do trabalho multiplicador dos professores e do envolvimento dos estudantes; e uma gratificante reação de surpresa por parte de pais, professores e dos próprios estudantes ao verificarem que, além de analisar poemas e crônicas, era possível também, sorrir e emocionar-se com os textos de Carlos Drummond de Andrade. 
Acreditamos, pois, que professores das mais variadas disciplinas podem encontrar, na obra, textos adequados a seus alunos e a seus objetivos. E, pensamos que, numa época como a nossa - de exacerbação do individualismo, de predomínio do "virtual", de incentivo constante a sobrepor-se ao próximo - temas como "afeto e solidariedade", trabalhados esteticamente por Drummond, tornam-se valores indispensáveis às relações humanas.

Convém ressalvar o reconhecimento do valor da poética drummondiana, por pessoas que conhecem grande parte da obra, ou que se identificam com um poema, ou crônica, em especial. Mas não podem,os ignorar a existência do estigma de "pessoa inacessivel, seca" por parte de muitos brasileiros, conforme foi perguntado ao próprio Carlos Drummond por Zuenir Ventura ${ }^{6}$ numa entrevista à Veja: "Tem-se do senhor uma imagem de pessoa inacessivel. 0 senhor continua seco, orgulhoso, de ferro, tal como no poema?"

0 poeta respondeu às perguntas, de forma bem-humorada, demonstrando serena consciência da existência desses "rótulos" e lembrando ao repórter que fora, durante grande parte de sua vida, funcionário público e jornalista - profissões ligadas direta ou indiretamente ao povo.

Apesar de todos os mitos e preconceitos, quando contextualizamos a produção poética de Drummond e demonstramos sua capacidade como artesão da palavra, para transformar um fato, aparentemente banal, do cotidiano de qualquer indivíduo, em arte universal e atemporal, atenua-se o mito. A imagem de "monstro sagrado" começa a desfazer-se, e o leitor se sente mais próximo do escritor, construindo a imagem de um poeta participante, que consegue dar forma artística às alegrias e tensões existenciais.

Esse especial afinamento de Drummond com sua época, seu compromisso com o estar presente, atento a seus semelhantes; a ternura contida em "Mãos dadas", em "Mundo grande" e tantos outros poemas e crônicas na temática de solidariedade todos esses motivos levaram-me à escolha do subtítulo da dissertação : afeto e solidariedade.

0 desejo de contribuir para amenizar a imagem referida, possibilitando ao leitor de Drummond uma reconstrução / ampliação da mesma, foi também um fator de 


\section{EMTESE}

Belo Horizonte, v. 8, p. I-243, dez. 2004

incentivo para pesquisar duas faces, a nosso ver, ainda pouco exploradas: - a do afeto aos familiares, extensivo não apenas aos seres humanos, mas também solidário com as árvores, as casas e cidades - e uma face bem-humorada que apresentamos no capítulo das "reminiscências" presentes principalmente na série Boitempo, cujos textos provocam risos e sorrisos no leitor.

Portanto, o objeto do trabalho foi a releitura da obra de Carlos Drummond de Andrade, focalizando a presença dos personagens da vida familiar real buscados no poema "A mesa" e retomados em outros textos ficcionais e documentais; visamos também suavizar / desconstruir uma imagem cristalizada, reconstruindo através do resgate de poemas e crônicas menos conhecidos - outra imagem mais abrangente, tanto da produção poética, quanto do homem que um dia existiu.

Quanto à abordagem, inspirei-me também num texto de Carlos Drummond "Vida e Memória"7 - em que o cronista, ao referir-se a autobiografias escritas pelos contemporâneos, pondera: "são válidas essas memórias de escritor?" Segundo ele, ninguém melhor do que o próprio escritor para manipular artísticamente a palavra, mas faz ressalvas sobre a retenção das experiências vividas, na memória, para o que chama de "balanço crepuscular".

Argumentando que o escritor deu-se ou devia ter se dado todo no que viu, viveu, imaginou e escreveu, explica que sua vida passou pela sua obra. E questiona se haveria ainda assunto para um livro. Caso haja, sugere: "Não seria melhor que esse livro fosse escrito por uma testemunha ingênua e veraz, ou por um grupo de testemunhas desse feitio, que restituisse, tanto quanto possivel, o ente comum imbricado na pessoa mítica do escritor?"

Nossa intenção é - juntamente com jornalistas que entrevistaram Carlos Drummond, com familiares que o conheceram e ancorada por depoimentos de críticos e estudiosos da obra - ser uma voz mediadora destas testemunhas, a fim de contribuir para uma visão ampliada do poeta e cronista. Buscamos resgatar, nessa obra multifacetada, as vertentes do afeto e da solidariedade vislumbradas em discretos, mas significativos gestos de humanidade revelados nas relações mais próximas, seja de parentesco, seja de convivência, como no caso da mãe preta Siá Maria.

A Dissertação, organizada em dois capítulos, tem como eixo, no primeiro deles, o texto "A mesa", publicado em 1951, em Claro Enigma na seção "Os lábios 
cerrados". Contendo trezentos e quarenta e um versos seguidos, sem nenhuma divisão em estrofes, como uma daquelas mesas de madeira inteiriça, usadas em fazendas mineiras, o texto reúne a família em torno do patriarca para comemorar, num jantar imaginário, seus noventa anos.

Nesse encontro, o poeta, como o porta-voz dos irmãos, apresenta os quatorze filhos ao pai e comenta sobre seus destinos. Persistindo na idéia de celebração, mas sem deixar de referir-se ao "respeito inibidor" dos jantares da infância, o eu-lírico cria um grande jantar mineiro, em clima espontâneo, onde "ririam de arrebentar", falariam de boca cheia e, após o vinho, trocariam confidências. 0 narrador cita, um a um, os outros seis filhos sobreviventes, incluindose também como personagem; em seguida, reverencia a mãe e dirige-se ao casal, constatando ao final, que a convocação aos familiares se dá por tanto amarem e desejarem o reencontro, e assim se iludirem junto da mesa, na realidade, vazia.

Cada personagem focalizado em "A mesa" com suas características mais peculiares é retomado na Dissertação, através de outros textos de Carlos Drummond. Por exemplo: Rosa é trazida na crônica "Agora pensei em Rosa", no poema "Nova moda" e numa carta de Drummond para a irmã, num cruzamento entre textos literários e documentais: fotografias, cartas, certidões de nascimento ou óbito, manuscritos, entrevistas, depoimentos de familiares. Esse primeiro capitulo, intitulado "As letras em jantar" subdivide-se em doze minicapítulos. Os três primeiros - dedicados aos irmãos em geral - têm como subtítulos, respectivamente: "0 porta-voz dos irmãos"; "Conta: quatorze na mesa" e "Os irmãos sobreviventes". Os seguintes trazem os nomes dos cinco irmãos que sobreviveram às doenças da infância:

* Rosa, flor delicada * Flaviano, fazendeiro de corpo e alma.

* Altivo e o país da literatura * José, o mel que transcende a raiva.

* Maria das Dores, a Mariinha.

Os próximos tratam da relação Carlos Pai x Carlos Filho e trazem como títulos:

* "A Palavra Poética: ao Pai, como Presente"

* "A Humanidade do Pai" 


\section{EM TESE}

Belo Horizonte, v. 8, p. I-243, dez. 2004

Há ainda nesse capítulo, mais duas subdivisões: uma, sobre D. Julieta Augusta - a mãe branca; outra, sobre o casal e sua ligação com o filho, incluindo situações de severidade, humor e amor:

* "Mãe - suave veludo"

* "As Bodas Místicas".

No segundo capítulo, apresentamos as "Reminiscências amenas". Sem perder de vista o fio condutor do afeto e da solidariedade, trazemos à luz textos que tratam dos prazeres sensoriais, do gozo estético, de momentos de peraltice em família e na escola, bem como expressões poéticas de ternura e encantamento diante dos menores seres e objetos. Dos prazeres gustativos do tabuleiro de quitanda aos de furtar jabuticaba na escola; dos auditivos, como o de ouvir o som do sino Elias e gritar ao eco "um som moleque" aos prazeres táteis: do banho no Poço da Água Santa ao calor dos braços da lavadeira; também são focalizados prazeres da casa paterna: "ler revista e nuvem", desenterrar minhocas, acompanhar formigas.

Ao dar ênfase a essas reminiscências, procuramos resgatar a dimensão de um poeta que reúne em sua obra o clássico e o popular, o soneto e o cordel, a forma metrificada e o verso livre. Drummond transita seguramente, de um texto complexo e hermético como "0 Jardim" de Novos poemas, a esses singelos e leves de Boitempo, ressignificando para as novas gerações aspectos de um passado familiar, religioso e social que, através do artesanato poético combinado ao fino humor drummondiano, podem emocionar o homem de qualquer tempo e lugar. Como as manifestações de ternura de Carlos Drummond não se esgotam no âmbito familiar - ou seja, na família consangüínea - mas se estendem aos seres humanos em geral, trazemos inicialmente a homenagem à Mãe Preta, dividindo esse capítulo em três subtítulos:

* "As mãos jardineiras de Sá Maria, a mãe preta"

* "Anjo Translúcido X Anjo Gauche"

* "Carlos Andrade - o Drummond".

Após focalizarmos Sá Maria em fragmentos de dez textos, trazemos a figura de um anjo translúcido ("delicadamente torto, pendido do lado do coração") encontrado em texto de Drummond e o associamos ao anjo gauche em "Anjo translúcido 
X Anjo Gauche". Nessa parte, damos ênfase a textos que indicam esperança em um mundo melhor e reafirmam a importância da afetividade. Pinçamos também em entrevistas, algumas"falas" que indicam profundo respeito ao outro e reverência ao mistério da vida. Por fim, em "Carlos Andrade - o Drummond", pode-se vislumbrar através de algumas declarações e depoimentos do próprio poeta e também de familiares e escritores contemporâneos como Pedro Nava, Abgar Renault, de jornalistas e pessoas que com ele conviveram, um ser humano simples, sensivel e solidário.

Quanto à relevância desta pesquisa para os estudos literários e para um resgate de história e memória cultural, pensamos que, ao pesquisar os textos literários, cruzando-os a documentos e fontes primárias reveladores de gestos afetivos, empenhamo-nos no sentido de preservar esses aspectos e, simultaneamente, de ampliar a imagem de Carlos Drummond que comumente tem sido levada às salas de aula. Esperamos que, neste segundo século de presença do poeta na literatura brasileira, a leitura da obra drummondiana se intensifique e seja cada vez mais valorizada.

NOTAS:

1. Morar em Itabira há quase quarenta anos propiciou-me identificação de fontes fidedignas de memória oral e acesso constante a documentos que se encontram em arquivos pessoais e públicos.

2. A artista plástica responsável pelos painéis é Yara Tupinambá, pintora mineira.

3. AYALA, 1987, p. 18

4. FIGUEIREDO, 1987. p.

5. Oficinas interativas cuja seleção de textos pautou-se por temas do cotidiano, nos quais simplicidade e solidariedade transparecessem. Lâminas com fotografias da familia, semântica musical adequada para introduzir os poemas, textos gravados com voz de Drummond e atores como Paulo Autran e Scarlet Moon também foram recursos utilizados.

6. VENTURA, 1980 , p. 3-8.

7. ANDRADE, 1989 , p. $95-6$ 


\section{EM TESE}

Belo Horizonte, v. 8, p. I-243, dez. 2004

ABSTRACT :

This essay is a rereading of Carlos Drummond de Andrade's literary work. It aims at rescuing the ancestral and emotional history of the Drummond/Andrade's family focusing on the poetical texts. It also intends to reveal the being present in the mythical figure of the poet and his familial relationship based on the affection and solidarity researched on his literary work, letters, documents, diary and interviews.

KEY WORDS: poetry, Drummond, family, affect, solidarity.

\section{REFERÊNCIAS BIBLIOGRÁFICAS}

ANDRADE, Carlos Drummond de. Nova Reunião: 19 livros de poesia. 2 ed. Rio de Janeiro: José 01 ympio, 1985. Vol.I e II. 969 p.

ANDRADE, Carlos Drummond de. Auto-retrato e outras crônicas. Rio de Janeiro: Record, 1989.

ANDRADE, Carlos Drummond de. Confissões de Minas. Rio de Janeiro: América Edit, 1944.

AYALA, Walmir. "Carta a Carlos Drummond de Andrade" Suplemento Literário Minas Gerais. Belo Horizonte: Imprensa Oficial. No especial: set. 1987.p. 18 